\begin{tabular}{|l|l|l|}
\hline \multicolumn{2}{|c|}{ PublisherInfo } \\
\hline \hline PublisherName & $:$ & BioMed Central \\
\hline \hline PublisherLocation & $:$ & London \\
\hline \hline PublisherImprintName & $:$ & BioMed Central \\
\hline \hline
\end{tabular}

\title{
Tissue deposits of hydroxyethyl starch (HES): dose-dependent and time-related
}

\begin{tabular}{|l|l|l||}
\hline \multicolumn{2}{|c||}{ ArticleInfo } \\
\hline \hline ArticleID & $:$ & 4100 \\
\hline \hline ArticleDOI & $:$ & $10.1186 /$ ccf-1999-189 \\
\hline \hline ArticleCitationID & $:$ & 189 \\
\hline \hline ArticleSequenceNumber & $:$ & 37 \\
\hline \hline ArticleCategory & $:$ & Paper Report \\
\hline ArticleFirstPage & $:$ & 1 \\
\hline \hline ArticleLastPage & $:$ & 4 \\
\hline \hline & & RegistrationDate : 1999-4-13 \\
\hline ArticleHistory & $:$ & OnlineDate \\
\hline \hline ArticleCopyright & $:$ & Current Science Ltd1999-4-13 \\
\hline \hline ArticleGrants & $:$ & \\
\hline \hline ArticleContext & $:$ & 130541111 \\
\hline \hline
\end{tabular}




\section{Keywords}

Blood, blood substitutes, colloids, fluid therapy, hydroxyethyl starch, pharmacology

\section{Comments}

As the use of HES may become more prevalent for fluid resuscitation, the concerns about long-term tissue effects should be addressed. This study appears to show that given time the HES deposits will ultimately be eliminated and are related to the dose of HES initially administered (level of evidence $=$ level V). All cases of severe pruritus were found in the high dose group. Clinicians in critical care medicine may find some comfort in these findings when searching for alternatives for plasma expansion.

\section{Introduction}

Much discussion has taken place over the last year about the relevant benefits of colloid and crystalloid, and the use of albumin solutions in the care of critically ill patients. Hydroxyethyl starch (HES) has been seen by some as an alternative to plasma volume replacement. However, HES administration is associated with tissue deposition in the cells of the reticulo-endothelial system. Such deposits have been demonstrated using immunohistochemistry and immuno-electron microscopy more than 2 years after administration. In most patients this appears to produce no problems but in a proportion of people, HES deposits are thought to cause severe untreatable pruritus. Before HES can become a suitable alternative to commonly used resuscitation fluids, such problems should be investigated more thoroughly.

\section{Aims}

This study aimed to examine tissue biopsies of patients, up to 7 years following HES administration, for the presence of HES deposits using light and electron microscopy, and immunohistochemical methods. 


\section{Methods}

Twenty-six patients who had received HES infusions were studied retrospectively. They had received HES between 1 day and 84 months previously. The patients were readmitted for surgery (for malignancy, chronic or bilateral orthopaedic disorders or other surgical indications) and informed consent was obtained to remove pea-sized tissue samples from the operative site (skin, liver, small intestine, striated muscle or spleen). Their previous records were examined and the date, duration of HES administration, dose and preparation of HES used noted. The patients were divided into two groups according to the dose of HES given (group A $2 \mathrm{~g} / \mathrm{kg}$ and group B 3-15 g/ $\mathrm{kg}$ ). The tissue samples were examined using light and electron microscopy and immunohistochemistry for evidence of HES deposits. The presence of deposits was quantified for each tissue sample in the same way, irrespective of the tissue of origin.

\section{Results}

HES deposits were mainly found in vascular endothelial cells and cells of the monocyte-macrophage system. HES deposits were found on all tissue samples (skin, liver, intestine, muscle, spleen) on the first day after HES administration.

In the patients who had received a smaller dose of HES (group A) HES deposits decreased with time and finally disappeared (after 15 months for liver and muscle and after 54 months for skin).

In group B patients who had received a higher dose of HES, 9 out of 10 patients had severe pruritus at the time of the first biopsy. Massive deposits of HES were seen in the skin but the size of deposit had much reduced at 3 years, by which time the pruritus had resolved in two of these patients.

\section{Discussion}

It appears from this study that tissue deposits of HES are both dose- and time-dependent.

Tissue deposition occurs with all colloid plasma substitutes and there is some indirect evidence that elimination occurs. This study shows that complete elimination of HES appears to happen in human tissues. Although HES deposits have little affect on patients clinically, some patients with chronic renal failure on dialysis have developed hepatosplenomegaly, portal hypertension and ascites with even small quantities of pentastarch. In this study, it was shown that the patients who have the greatest dose exposure to HES had the longest duration of tissue deposits. Patients who received hetastarch also had a longer duration of deposits compared to those who received pentastarch. 
The authors felt that these results may be due to differences in fluid status or kidney function at the time of administration which altered the initial elimination of HES from the circulation. They also speculated that the differences seen in the tissue samples may be due to blood loss eliminating HES or metabolic variations.

Skin is the most involved organ and where the deposits had longest duration. Only patients who had received between 3 and $15 \mathrm{~g} / \mathrm{kg}$ had any problems with pruritus.

Therefore, it appears that the amount of tissue deposition and the duration of such deposits is related to the dose of HES given. These deposits are cleared with time.

\section{References}

1. Stirl C, Laubenthal H, Zumtobel V, Kraft D, Jurecka W: Tissue deposits of hydroxyethyl starch (HES): dose-dependent and time-related. Br J Anaesth. 1999, 82: 510-515. 